\title{
Understanding and Solving Biomass Feeding and Handling Challenges
}

\author{
Tyler L Westover*, Yidong Xia and Jordan Klinger \\ Idaho National Laboratory, USA
}

Submission: May 02, 2018; Published: May 21, 2018

"Corresponding author: Tyler L Westover, Idaho National Laboratory, Energy Systems Laboratory, 750 University Blvd, USA , Tel: 208-526-1553; Fax: 208-526-3150; Email: tyler.westover@inl.gov

\begin{abstract}
Preprocessing, handling, and feeding diverse materials is a substantial challenge in industrial systems that handle agricultural residues and other lignocellulosic materials. This mini review summarizes those challenges and briefly describes how advanced computational models can assist in overcoming them.
\end{abstract}

Keywords: Biomass; Agricultural residues; Bulk solid; Particle; Feeding; Handling; Rheology

\section{Mini Review}

Preprocessing, handling, and feeding diverse materials is a substantial challenge in industrial systems that handle agricultural residues and other lignocellulosic materials. Feeding, conveying, and storage systems for that work well for conventional dry bulk solids are generally not suitable for lignocellulosic biomass that has low density and high compressibility. As a result, scale-up of laboratory and pilot scale plants to industrial scale systems has been a major challenge for biorefineries. For example, in the US in 2016 cellulosic ethanol production was only about $7 \%$ of the nameplate production capacity of 58 million gallons per year [1]. Improvements are being made, but much of the increase in recent production is due to a new EPA ruling that classified corn kernel fiber as a crop residue with an associated Renewable Identification Number (RIN) [2]. Alleviating the material preprocessing and handling problems is a major milestone for biorefineries as was recently shown in a press release by POET-DSM, in which they reported a cellulosic biofuel breakthrough by achieving $80 \%$ time onstream over a period of two weeks [3].

A book chapter has recently summarized research indicating the limitations of current methods to measure the required material properties and design equipment to robustly handle biomass, including agricultural residues [4]. Ingeneral, traditional quantitative design methods to handle particulate materials are limited to materials that are relatively incompressible, have small particles (less than a few millimeters), and are handled at consolidation pressures larger than approximately $2 \mathrm{kPa}$.
In many cases, processes that handle agricultural residues for biofuels applications do not meet these criteria, and handling problems often result $[5,6]$. For a limited range of applications, purely empirical methods may be used to successfully design equipment by performing laboratory tests using conditions that are similar to those that are expected in industrial operations; however, extending those predictions to a wide range of conditions is not practical due to the large number of variables, many of which are nonlinearly related [4]. Understanding the mechanical behavior of challenging biomass materials will likely require close coupling between instrumented lab and pilot scale tests and multiscale modeling.

Current design methods for equipment and processes that handle particulate materials are primarily limited by their reliance on material models that are based upon very simple elastic and plastic behavior models. A range of newer models with varying levels of sophistication have been developed. Here we briefly summarize some of the more promising models. Advanced computational models generally fall into two categories:

A. Those that apply the discrete element method (DEM) to simulate the motion and even the deformation of each particle in the flow field, and

B. Those that assume the material behaves like a continuous material and employ the finite element method (FEM) to calculate the material flow (deformation) in terms of pseudo stresses and strains. 
DEM models are inherently more realistic for particulate materials and are widely used for modeling particulate materials that can be approximated using relatively simple shapes such as spheres, cuboids and ellipsoids [7]. Modeling the flow of particles with more complex shapes or that can deform requires more advanced models [8,9]. Figure 1 shows the predicted cumulative mass flow of spherical particles in a wedge-shaped hopper as the side panels are slowly lifted upwards. A distinguishing feature of the flow is that it is episodic instead of continuous or uniform. The particles tend to flow in packets with much of the sliding and rolling friction occurring along narrow regions that are sometimes referred to as shear bands. These results agree with recent physical tests using corn stover and pine chip residues conducted at INL [unpublished result]. Modeling the motion of each particle has very high computational cost and is only feasible for a few million particles at most, even with high performance computing, so that DEM simulations can typically only be applied at laboratory scale.

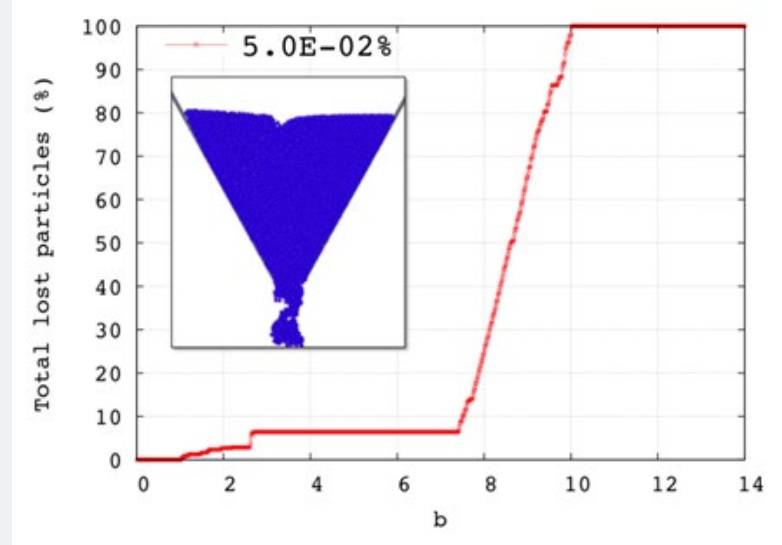

Figure 1: Predicted cumulative mass flow of spheres in a hopper with moving walls using the DEM. The "b" on the x-axis denotes the opening width of the hopper bottom normalized by the average effective particle diameter.

As mentioned above, the other modeling approach averages over many particles to reduce the computational burden and calculates the flow field in terms of continuous material velocities and stresses. This second modeling approach typically employs the finite element method (FEM) with different material models to account for the effects of elasticity (temporary deformation), plasticity (permanent deformation), and viscosity (fluid-like flow). Traditional approaches, such the Drucker-Prager and Cam-Clay models were developed to simulate hardening effects during pelleting or soil mechanics and typically cannot account for complex flow behavior, such as shear banding that may be present in biomass flow. To capture these complex phenomena, more advanced simulations are required that introduce additional particle-type or multiscale effects [10]. Current work that is supported by the US Department of Energy includes efforts to develop DEM, Drucker-Prager Cap, and modified CamClay, as well as more advanced methods to better understand feeding and handling behavior of biomass $[11,12]$. These efforts will include close coupling between lab and pilot scale tests with multiscale modeling as suggested above to better understand and solve biomass feeding and handling challenges.

\section{Financial and conflict of interest disclosure}

The views expressed in the article do not necessarily represent the views of the U.S. Department of Energy or the United States Government. The authors have no other relevant affiliations or financial involvement with any organization or entity with a financial interest in or financial conflict with the subject matter or materials discussed in the manuscript apart from those disclose.

\section{Acknowledgments}

The research was supported by the U.S. Department of Energy (DOE), Office of Energy Efficiency and Renewable Energy (EERE), Bioenergy Technologies Office (BETO), under DOE Idaho Operations Office. Contract DE-AC07-05ID14517.

\section{References}

1. Kenney KL, Ramirez-Corredores M, Wolfrum E, Elander R (2017) Feedstock-Conversion Interface (FCIC). USDOE BETO 2017 Project Peer Review, Colorado, USA.

2. Erickson B. (2018) A Rising Tide of Cellulosic Ethanol Production, Indust. Biotechnol 14(2).

3. Kennedy HT (2017) Breaking the Bottleneck - POET-DSM achieves cellulosic biofuel breakthrough, Biofuels Digest.

4. Westover T, Hartley D (2018) "Biomass Feeding and Handling” in book Biofuels - Past, Present and Future. In: M Nageswara-Rao, J Soneji (Eds.), In-Tech Publishing (final production stage with expected publication in May 2018).

5. Barletta D, Poletto M (2013) An assessment on silo design procedures for granular solid biomass, Chem Engin Trans 32: 2209-2214.

6. Hernandez S, Westover TL, Ryan JC, Matthews AC, Williams CL, et al. (2017) Feeding properties and behavior of hammer- and knife-milled pine. Powder Technol 320: 191-201.

7. Coetzee CJ (2017) Calibration of the discrete element method. Powder Technol 310: 104-142.

8. Zhong W, Yu A, Lui X, Tong Z, Zhang H, et al. (2016) DEM/CFD-DEM modelling of non-spherical particulate systems: theoretical developments and applications. Powder Technol 302: 108-152.

9. Guo Y, Wassgren C, Curtis JS, Xu D (2018) A bonded sphero-cylinder model for the discrete element simulation of elasto-plastic fibers. Chemical Engineering Science 175: 118-129.

10. Wójcik M, Tejchman J (2009) Modeling of shear localization during confined granular flow in silos within non-local hypoplasticity, Powder Technol. 192: 298-310.

11. www.energy.gov/articles/secretary-energy-rick-perry-announcesintegrated-biorefinery-optimization-projects

12. www.fcic.inl.gov 
This work is licensed under Creative

Commons Attribution 4.0 License

DOI: 10.19080/ARTOAJ.2018.16.555984
Your next submission with Juniper Publishers will reach you the below assets

- Quality Editorial service

- Swift Peer Review

- Reprints availability

- E-prints Service

- Manuscript Podcast for convenient understanding

- Global attainment for your research

- Manuscript accessibility in different formats ( Pdf, E-pub, Full Text, Audio)

- Unceasing customer service

Track the below URL for one-step submission https://juniperpublishers.com/online-submission.php 